\title{
Modelos para evaluar la situación de las bibliotecas escolares y la calidad de sus sitios web
}

Irene González Mateos

Cristina Faba Pérez *

Artículo recibido:

23 de abril de 2013.

Artículo aceptado:

19 de noviembre de 2013.

\section{Resumen}

El presente trabajo tiene dos objetivos: desarrollar un modelo exhaustivo de 44 indicadores para evaluar el funcionamiento o la situación de las bibliotecas escolares; y diseñar un modelo específico de 30 características para valorar objetivamente la calidad de los sitios web de las bibliotecas escolares. Además, se lleva a cabo la aplicación práctica de ambos modelos sobre las bibliotecas escolares de la ciudad de Badajoz (en la región de Extremadura, España) en 2012 con la finalidad de comprobar la validez de los modelos y obtener un ranking de las bibliotecas atendiendo a su situación y a la calidad de sus sitios web. Entre los resultados hallados se demuestra que no existe correlación entre

Las dos autoras pertenecen a la Universidad de Extremadura, Badajoz, España. (igonmat@alcazaba.unex.es), (cfabper@unex.es)

INVESTIGACIÓN BiBLIOTECOLÓGICA, Vol.28, Núm. 63, mayo/agosto, 2014, México, ISSN: 0187-358X. pp. 29-50 
el ranking obtenido por las bibliotecas escolares atendiendo a su situación actual y al ranking de calidad de sus sitios web.

Palabras clave: Bibliotecas escolares; Modelos de evaluación; Funcionamiento; Sitios web; Badajoz.

\section{Abstract}

Models for evaluating the condition of school-based libraries and the quality of their web sites

Irene González-Mateos and Cristina Faba-Pérez

This paper approaches two objectives: 1) to develop a comprehensive model of 44 indicators to assess the performance or status of school libraries, and 2) to design a specific model of 30 objective features to assess the quality of school-based library web sites. In 2012, researchers documented the practical implementation of both models in school-based libraries in the City of Badajoz located in the region of Extremadura, Spain, in order to ascertain indicator validity and develop a library ranking in accord with operational quality of the respective websites. The results show that there is no correlation between the rank of school libraries based on current conditions and the quality rank of their associated websites.

Keywords: School libraries; Evaluation Models; Performance; Websites; Badajoz.

\section{INTRODUCCIÓN}

$\mathrm{E}$ l interés por el estudio de las bibliotecas escolares en España se ve reforzado progresivamente por las distintas Leyes Nacionales de Educación surgidas a partir de 1990 (LOGSE 1990, ${ }^{1}$ LOCE 2002, ${ }^{2}$ LOE $2006^{3}$ y LOMCE

1 LOGSE, Ley 1/1990, de 3 de Octubre, de Ordenación General del Sistema Educativo (BOE 3/10/1990).

2 LOCE, Ley Orgánica 10/2002, de 23 de Diciembre, de Calidad de la Educación (BOE 24/12/2002). 
2012 $)$. El objetivo primordial de las bibliotecas escolares es servir a toda la comunidad educativa no universitaria, siendo éstas un elemento clave para: a) apoyar el trabajo de alumnos y profesores; b) desarrollar habilidades de información y formar en el uso de fuentes de información; c) apoyar el desarrollo del currículo y la consecución de objetivos; d) desarrollar la autonomía de aprendizaje y la capacidad de aprender durante toda la vida. Hoy en día, el modelo educativo que implica aprender a utilizar la información se conoce como Alfabetización en Información (ALFIN) o Competencia Informacional. Según la American Library Association (ALA, 1989), la Alfabetización Informacional genera personas que han aprendido cómo aprender y que saben cómo hacerlo porque conocen cómo está organizado el conocimiento, cómo encontrar la información y cómo usarla para que otros puedan aprender de ellos.

Ahora bien, para que la biblioteca escolar proporcione un adecuado aprendizaje a sus usuarios son necesarias dos condiciones: que funcione correctamente y que no se quede al margen de las tecnologías de la información y la comunicación y, por consiguiente, de Internet y de la World Wide Web. Para comprobar ambas premisas es preciso desarrollar modelos que permitan evaluar tanto el funcionamiento o la situación de las bibliotecas escolares como las características de sus sitios web.

Para valorar la situación de las bibliotecas escolares a nivel internacional, existen Organismos como International Association of School Librarianship (IASL), European Network for School Libraries and Information Literacy (ENSIL) o The International Federation of Library Associations and Institutions (IFLA), que en sus School Library Guidelines (2002) enumera una lista de indicadores de evaluación cuya aplicación permite conocer la realidad de las bibliotecas escolares en los diversos ámbitos geográficos. En el contexto geográfico de España se han desarrollado documentos oficiales y realizado evaluaciones nacionales promovidas por grandes entidades como la Federación Española de Asociaciones de Archiveros, Bibliotecarios, Arqueólogos, Museólogo y Documentalistas (ANABAD), la Federación Española de Sociedades de Archivística, Biblioteconomía, Documentación y Museística (FESABID) (1997), la Fundación Germán Sánchez Ruipérez (FGSR) (Marchesi y Miret, 2005) o el Ministerio de Educación (2011). En el ámbito regional, en concreto de Extremadura, también existen algunas investigaciones sobre la situación de las bibliotecas escolares (Faba-Pérez, 2000; Junta de Extremadura, 2006; Pomet Correa, 2006; Tejero Aparicio, 2006; Cruz Solís, 2008).

4 LOMCE, Ley Orgánica de Mejora de la Calidad Educativa, Versión 2 03/12/2012. Disponible en http://www.ara.cat/societat/esborrant-lomce_ARAFIL20121203_0003.pdf 


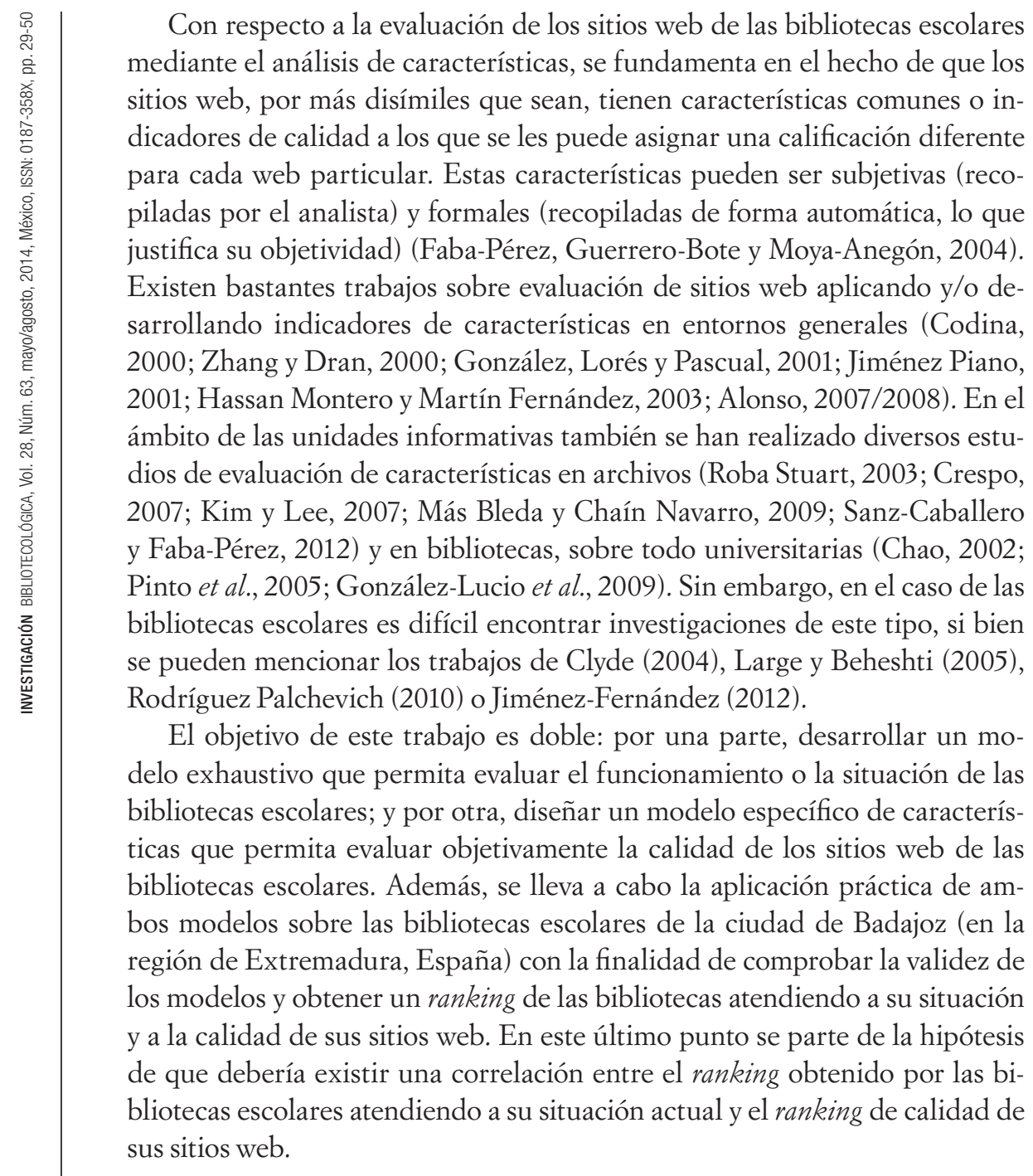

\section{Datos y METODOlOgía}

\section{Datos}

La aplicación práctica de los modelos diseñados en la presente investigación y que se detallan en la Metodología se ha realizado sobre las bibliotecas escolares de los Institutos de Enseñanza Secundaria (IES) y los Colegios de Educación 
Infantil y Primaria (CEIP) públicos y privados/concertados de la ciudad de Badajoz durante el año 2012 (49 centros). La fuente oficial usada para recopilar los centros educativos ha sido EDUCAREX (http://www.educarex.es/web/ guest/listado-centros), de la Consejería de Educación y Cultura de Extremadura. De los 49 centros iniciales participan en el estudio un total de 30 (Tablas I y II), que son los que responden al modelo diseñado.

Tabla I. Datos de participación.

\begin{tabular}{|c|c|c|c|c|}
\hline \multicolumn{2}{|r|}{ Centros } & Iniciales & Finales & Porcentaje de participación \\
\hline \multicolumn{2}{|r|}{ Institutos } & 11 & 8 & $72.73 \%$ \\
\hline \multirow[b]{2}{*}{ Colegios } & Públicos & 25 & 19 & $76.00 \%$ \\
\hline & Privados/concertados & 13 & 3 & $23.08 \%$ \\
\hline \multicolumn{2}{|r|}{ Total } & 49 & 30 & $61.22 \%$ \\
\hline
\end{tabular}

Tabla II. Listado de centros participantes.

\begin{tabular}{|l|l|l|}
\hline \multicolumn{1}{|c|}{ IES } & \multicolumn{2}{c|}{ CEIP (públicos y privados/concertados) } \\
\hline Bárbara de Braganza & Arias Montano & Manuel Pacheco \\
\hline Castelar & Cerro de Reyes & Ntra. Sra. de Bótoa \\
\hline Reino Aftasí & Enrique Iglesias García & Ntra. Sra. de Fátima \\
\hline Rodríguez Moñino & Enrique Segura Covarsí & Ntra. Sra. de la Soledad \\
\hline San Fernando & General Navarro & Puente Real \\
\hline San José & Juan Vázquez & San José de Calasanz \\
\hline San Roque & Juventud & Santa Marina \\
\hline Zurbarán & Leopoldo Pastor Sito & Santo Tomás de Aquino \\
\hline & Lope de Vega & Diocesano (San Atón) (privado) \\
\hline & Luis de Morales & Jesús Obrero (privado) \\
\hline & Luis Vives & Sagrada Familia (privado) \\
\hline & & 22 \\
\hline
\end{tabular}

\section{Metodología}

\section{Método para evaluar la situación de las bibliotecas escolares}

Primero se diseña un modelo exhaustivo que recoge los aspectos más importantes sobre su funcionamiento. Dicho modelo se compone de 44 cuestiones agrupadas en seis categorías principales (con sus respectivas subcategorías): A. Dotación de la biblioteca, B. Biblioteca escolar y centro, C. Recursos documentales, D. Presencia de la biblioteca escolar en Internet, E. Local y dotación de equipos, F. Funcionamiento y gestión. Con el fin de no duplicar la información, las 44 cuestiones del modelo se irán mostrando junto a los resultados del estudio aplicado. 
La información obtenida en cada una de las 44 cuestiones en cada uno de los participantes se analiza con el objetivo de realizar un estudio conjunto o global de la información aportada por los 30 centros participantes y para obtener una aproximación general sobre la situación real de las bibliotecas escolares en la ciudad de Badajoz en el 2012.

Finalmente, se realiza un ranking individualizado de las bibliotecas escolares atendiendo a la situación particular de cada una de ellas en relación con el modelo diseñado. Para ello se procede a matizar y depurar cada una de las cuestiones del modelo, con lo que las 44 cuestiones originales se reducen a 32, y se comprueba la presencia (1) o la ausencia (0) de cada cuestión en el modelo cumplimentado por cada centro.

\section{Método para evaluar los sitios web de las bibliotecas escolares}

En primer lugar, se diseña un modelo de 30 características para evaluar de sitios web de bibliotecas escolares con dos tipos de características: 10 generales y 20 específicas. Las primeras permiten tener una visión global de cómo debe ser una web destinada a un alumnado de primaria y secundaria y resultan de la consulta de algunos trabajos como Marquès Graells (1999), Jiménez Piano (2001) o Sanz-Caballero y Faba-Pérez (2012); mientras que las características específicas imprescindibles en una web de bibliotecas escolares son fomento de las TIC, retroalimentación por parte del alumnado, aportaciones educativas, etc. Para recopilarlas se han consultado webs específicas de bibliotecas escolares y trabajos de autores en este ámbito, como Marquès Graells (2001), Clyde (2004) y Large y Beheshti (2005) (Tabla III).

Tabla III. Modelo de características para la evaluación de webs de bibliotecas escolares.

\begin{tabular}{|c|c|}
\hline Características & Significado \\
\hline \multicolumn{2}{|c|}{ Generales } \\
\hline 1. ¿Posee una URL clara? & $\begin{array}{l}\text { A través de la URL se puede reconocer fácilmente que } \\
\text { pertenece a la biblioteca del colegio o instituto. } \\
\end{array}$ \\
\hline 2. ¿Es fácil la navegación? & $\begin{array}{l}\text { Facilidad para acceder a cualquier parte del sitio } \\
\text { web. }\end{array}$ \\
\hline 3. ¿Es amigable, familiar y cercana? & $\begin{array}{l}\text { Presenta una estructura manejable y asequible al } \\
\text { usuario. }\end{array}$ \\
\hline 4. ¿No tiene sobrecarga informativa? & $\begin{array}{l}\text { Se consigue haciendo un uso correcto de colores, } \\
\text { efectos tipográficos y agrupaciones para discriminar } \\
\text { información. }\end{array}$ \\
\hline 5. ¿Posee un lenguaje claro y conciso? & $\begin{array}{l}\text { Usa un lenguaje adecuado para los alumnos de } \\
\text { infantil, primaria o secundaria. }\end{array}$ \\
\hline 6. ¿Se cuida la gramática y la ortografía? & $\begin{array}{l}\text { La información debe encontrarse bien redactada y no } \\
\text { deben existir errores ortográficos. }\end{array}$ \\
\hline
\end{tabular}




\begin{tabular}{|l|}
\hline 7. ¿Existe cierta regularidad en las actualizaciones \\
informativas de la web? \\
\hline 8. ¿Aporta un diseño coherente? \\
\hline $\begin{array}{l}\text { 9. ¿Existe una persona o grupo de personas que se } \\
\text { ocupan del mantenimiento? }\end{array}$ \\
\hline $\begin{array}{l}\text { 10. ¿Se puede mantener contacto con los responsa- } \\
\text { bles del sitio web? }\end{array}$ \\
\hline
\end{tabular}

Teniendo en cuenta que se trata de una web de carácter educativo, es importante que ofrezca información actualizada.

El sitio web debe ser visualmente agradable (colores cálidos, letra legible, etc.).

El sitio web favorece la clara identificación de los responsables de su mantenimiento.

Facilidad para contactar con los administradores (e-mail, número de teléfono, etc.).

11. ¿El sitio web realiza un seguimiento de las actividades de la biblioteca escolar en el centro?

Específicas

12. ¿El sitio web realiza un seguimiento de las actividades del centro educativo?

\begin{tabular}{l} 
13. ¿Fomenta la lectura? \\
\hline $\begin{array}{l}\text { 14. ¿Tiene enlaces a instituciones relacionadas con } \\
\text { la biblioteca escolar? }\end{array}$
\end{tabular}

15. ¿Proporciona enlaces a recursos didácticos?

16. ¿Proporciona materiales para trabajar en línea?

17. ¿Permite a los alumnos/as incluir sus creaciones?

Indica todas las actividades realizadas en la biblioteca: talleres, teatro, club de lectura, etc.

Indica todas las actividades realizadas en el centro: excursiones, premios, novedades, etc.

Recomienda lecturas, realiza juegos lectores, informa de novedades sobre libros, etc.

Especifica enlaces a otras web con información pertinente (otras bibliotecas, otros centros, etc.).

Especifica enlaces de apoyo para las asignaturas y los docentes.

Por ejemplo: fichas para colorear, libros en línea, juegos, etc.

El sitio web permite que los alumnos den a conocer sus cuentos, dibujos, etc.

18. ¿Presenta un contenido proporcionado para la comunidad escolar?

Aunque el contenido esté enfocado al alumnado, no deja al margen otros colectivos como el profesorado.

19. ¿Proporciona un material adecuado e innovador?

20. ¿Presenta aspectos dinámicos?

El material debe ser original y adecuado para la franja de edad a la que va destinada.

Tiene un diseño atrayente para los alumnos, con animaciones (fotografías, videos, colorido, etc.).

21. ¿Las imágenes que aparecen en el sitio web de la biblioteca están correctamente nombradas?

Es importante que las imágenes y demás recursos estén correctamente nombrados e indiquen la fuente de los mismos

22. ¿Permite acceder fácilmente al material publicado con anterioridad?

Es beneficioso poder acceder a publicaciones antiguas de manera rápida para realizar consultas, trabajos, etc.

23. ¿Dispone de un catálogo en línea de los fondos de la biblioteca escolar?

Es importante que los catálogos se encuentren automatizados y el alumnado pueda buscar lo que desee dentro y fuera del centro.

24. ¿Permite descargar material audiovisual? Permite descargar recursos audiovisuales necesarios para la enseñanza (videos, imágenes, canciones, etc.).

25. ¿Existe interacción por parte del alumnado en el sitio web de la biblioteca?

El alumnado puede realizar comentarios, publicaciones, etc.

26. ¿La biblioteca escolar tiene una mascota o logotipo identificativo?

Es importante que la web de la biblioteca refleje este hecho, porque de esta manera el alumnado rápidamente identificará la biblioteca escolar. 

27. ¿Promueve el uso de las tecnologías de la infor-
mación y la comunicación?

28. ¿El sitio web facilita una lectura rápida del mismo?

29. ¿Tiene servicios de apoyo en línea?

30. ¿Es una web multilingüe?
Debe proponer actividades que favorezcan el desarrollo de habilidades tales como la consulta, búsqueda, selección, valoración, etc.

El contenido de las aportaciones debe ser en textos breves, ya que facilita su lectura.

Existen foros, chat, grupos de trabajo, etc.

Debido a la existencia cada vez mayor de alumnado extranjero, es importante ofrecer contenido multilingüe.

En segundo lugar se realiza un ranking individualizado de las bibliotecas escolares atendiendo a la calidad de sus sitios web según el modelo diseñado. Para indicar si se cumplen dichas características, se identifica en los sitios web el grado de cumplimiento de las características con el siguiente baremo de puntuación: 0 deficiente, 0,5 suficiente y 1 notable.

\section{Resultados}

\section{Evaluación de la situación de las bibliotecas escolares}

A continuación se muestra el modelo para evaluar la situación de las bibliotecas escolares y los resultados globales porcentuales obtenidos sobre el funcionamiento de las bibliotecas de los institutos y colegios de Badajoz, teniendo en cuenta las respuestas dadas a cada una de las 44 cuestiones planteadas en el modelo (Tabla IV).

Tabla IV. Modelo y resultados sobre la situación de las bibliotecas escolares.

\begin{tabular}{|l|}
\hline \multicolumn{1}{|c|}{ A. Dotación de la biblioteca } \\
\hline $\begin{array}{l}\text { 1. ¿Dispone el Centro de servicio bibliotecario? Opciones: Central, Aula, Departamento, Central+Aula, Nin- } \\
\text { gún tipo, Ns/Nc }\end{array}$ \\
\hline $\begin{array}{l}\text { El } 100 \% \text { de los centros educativos analizados disponen de biblioteca escolar. La mayoría de los institutos } \\
\text { tienen actualmente biblioteca de tipo central (62 \%), y más del 91\% de los colegios tienen biblioteca centraly } \\
\text { de aula, frente al } 25 \% \text { de los institutos. }\end{array}$ \\
\hline \multicolumn{1}{|c|}{ B. Biblioteca escolar y centro } \\
\hline B.1. Integración de la biblioteca en el centro educativo \\
\hline $\begin{array}{l}\text { 2. ¿Existe una biblioteca de uso exclusivo para el profesorado? Opciones: Sí, No, Ns/Nc } \\
\text { sólo el } 12 \% \text { de los institutos y el 14 \% de los colegios tienen una biblioteca de uso exclusivo para el profe- } \\
\text { tipos de usuarios. }\end{array}$ \\
\hline $\begin{array}{l}\text { 3. ¿A qué colectivos sirve la biblioteca escolar? Opciones: Alumnos, Profesores, Otros (ex-alumnos, padres, } \\
\text { etc.) }\end{array}$ \\
\hline
\end{tabular}


La mayoría de los centros analizados centran sus servicios en el alumnado y el profesorado de manera general, no exclusiva. En los institutos, el $42 \%$ de los casos oferta servicios para el alumnado y el mismo porcentaje para los profesores. En los colegios también es mayoritario servir a los alumnos (41\%) y a los profesores (37\%) que a otros colectivos.

4. ¿Existe un plan de trabajo anual para la biblioteca escolar? Opciones: Sí, No, Ns/Nc

Es importante que la biblioteca escolar se encuentre organizada, por lo que es imprescindible que exista un plan de trabajo anual sobre sus objetivos a lo largo del curso. Los centros educativos analizados cumplen satisfactoriamente esta característica, ya que en los institutos el $62 \%$ de los casos tienen un plan de trabajo anual, y en los colegios es mucho más amplio (86 \%).

B.2. Relación de la biblioteca con otras instituciones

5. ¿Tiene relación la biblioteca escolar con bibliotecas públicas cercanas? Opciones: Sí, No, Ns/Nc

La relación con las bibliotecas públicas es fundamental para fomentar en los alumnos el hábito de ir a la biblioteca y facilitar el fomento de la lectura. En los institutos esta relación es prácticamente inexistente (12 \%) y en los colegios es algo mayor, pero insuficiente $(25 \%)$.

6. ¿Tiene relación con el Centro de Profesores y Recursos (CPR)? Opciones: Sí, No, Ns/Nc

Mantener una relación con el cpr es importante ya que suelen realizar seminarios sobre educación, lectura, etc. que sirven de complemento a las actividades de la biblioteca escolar. Actualmente sólo el 37 \% de los institutos mantiene algún contacto con el cpr frente al $59 \%$ de los colegios. Un dato preocupante es que el $13 \%$ de los institutos no conozca si dicha relación existe o no.

C. Recursos documentales de la biblioteca escolar

C.1. Constitución de los fondos documentales

7. ¿Qué contenido tiene el fondo de la biblioteca escolar? Opciones: Material de conocimiento/consulta, Material de literatura/ficción, Álbumes, Tebeos, Revistas, Material elaborado por los alumnos, Mapas, Material audiovisual, Juegos, Objetos, Otros

El fondo disponible en mayor medida en los institutos y en los colegios es el material de consulta y conocimiento, aunque con unos porcentajes relativamente bajos (23 \% y $16 \%$ respectivamente). Este material se encuentra seguido en los institutos por tebeos, fondo elaborado por los alumnos y material audiovisual (18\%) y complementado en los colegios por material audiovisual (16\%). Es significativo que el material de literatura y ficción aparezca sólo en el $17 \%$ de los institutos y en el 14 \% de los colegios, así como el material audiovisual (cada vez más importante en la nueva sociedad de la información), también con porcentajes bastante bajos (18\% en los institutos y $16 \%$ en los colegios).

8. ¿Cuántos volúmenes integran el fondo de la biblioteca escolar? Opciones: <1000, 1000-3000, 3000$5000,5000-10000,>10000$, Ns/NC

Según las directrices de la IFLA/Unesco para las bibliotecas escolares (2002): "[...] Es recomendable que por lo menos cuenten con al menos 2500 títulos relevantes y actuales para garantizar un stock de libros equilibrado para todas las edades, habilidades e historias personales". En los centros educativos de Badajoz se cumple dicha directriz, ya que el $63 \%$ de los institutos encuestados poseen más de 10000 volúmenes y el $56 \%$ los colegios indican que tienen entre 3000-5000.

9. ¿Se revisan anualmente los fondos de la biblioteca escolar? Opciones: Sí, No, Ns/Nc

La revisión anual de los fondos de la biblioteca escolar es importante, ya que es una manera de mantener actualizado el material y ver en qué estado se encuentra. En el caso de los institutos de Badajoz, esta revisión es ambigua: en el $50 \%$ de los casos sí la realizan, pero el otro $50 \%$ no. Por el contrario, en el $91 \%$ de los colegios sí se procede a una revisión anual de los fondos.

10. Si la respuesta anterior es afirmativa, ¿qué criterio de revisión de fondos se sigue? Opciones: Estado de material, Actualización de la información, Frecuencia de uso, Otros, Ninguno, Ns/Nc

En los institutos los criterios más usados son estado del material y frecuencia de uso (con un $33 \%$ en ambos casos). En cambio, en el $45 \%$ de los colegios el criterio más usado es el estado del material, seguido de la actualización de la información (25 \%) y la frecuencia de uso (22 \%). Un resultado muy positivo es que el 100 $\%$ de las bibliotecas escolares de Badajoz usa algún criterio de revisión. 
11. ¿Cuál es el destino del material inservible de la biblioteca escolar? Opciones: Se da de baja, No se da de baja, Ns/Nc

Después de proceder a la revisión de los fondos, debe existir un destino de aquellos materiales que se encuentren inservibles o no sean adecuados para permanecer en la biblioteca escolar. En el $63 \%$ de los institutos no se dan de baja, sin embargo, en los colegios en el $95 \%$ de los casos sí se da de baja el material inservible.

12. ¿Qué número de fondos se ingresan anualmente en la biblioteca escolar? Opciones: 0, 1-100, 101-300, $>300, \mathrm{Ns} / \mathrm{Nc}$

En los centros educativos de Badajoz, el número de fondos que ingresan anualmente en la biblioteca escolar de los institutos se reparte entre el $50 \%$ de los casos que ingresan una media de 1-100 volúmenes y el otro $50 \%$ que ingresa entre 101-300 volúmenes. En los colegios, el $48 \%$ de los centros encuestados ingresan una media de 1-100 volúmenes.

C.2. Automatización y organización de los fondos

13. ¿Se encuentra el fondo automatizado? Opciones: Sí, No, Ns/Nc

Con las nuevas tecnologías, la mayoría de los centros educativos de Badajoz tienen automatizado el fondo de su biblioteca escolar, lo que facilita mucho el control del mismo. El $100 \%$ de los institutos tiene automatizados los fondos, los colegios algo menos ( $86 \%)$.

14. Si la respuesta anterior es afirmativa, ¿utiliza el programa abies? Opciones: Sí, No, Ns/Nc

La incorporación del programa ABIES en las bibliotecas escolares (distribuido de manera gratuita en todos los centros educativos de Extremadura públicos y concertados) ha permitido que la mayoría de ellas se automatice. Debido a ello, el $100 \%$ de los institutos y el $89 \%$ de los colegios que sí tienen automatizados sus fondos utilizan el programa ABIES.

15. ¿Tiene libro de registro? Opciones: Sí, No, Ns/Nc

El $62 \%$ de los institutos y el $59 \%$ de los colegios encuestados sí poseen un libro de registro. Lo alarmante es el porcentaje de institutos y colegios sin libro de registro (38 \% y $41 \%$, respectivamente), ya que es el inventario de los fondos que posee la biblioteca y donde se incluyen todos los documentos que forman la colección. Teniendo en cuenta que ABIES genera un listado de los fondos de la biblioteca y que el $100 \%$ de los institutos y el $89 \%$ de los colegios usaban dicho programa, es probable que la persona encargada de rellenar el modelo no haya asociado dicho listado con un libro de registro de fondos, de ahí el elevado porcentaje de centros que han respondido no disponer de libro de registro.

16. Si la respuesta anterior es afirmativa, ¿es manual o automatizado? Opciones: Manual, Automatizado

En aquellas bibliotecas escolares que indicaron que sí poseían libro de registro, el $50 \%$ de los institutos 10 tienen manual y el otro $50 \%$ automatizado (siguiendo el razonamiento de la pregunta 15 , si el $100 \%$ de los institutos usan ABIES, todos dispondrán de libro de registro automatizado, por eso el $50 \%$ que dice poseerlo manual es porque, además, dispondrá de un libro de registro manual). En los colegios, el $100 \%$ lo presenta automatizado.

17. ¿Tienen catálogos? Opciones: Sí, No, Ns/Nc

Respecto a si tienen catálogos, el $63 \%$ de los institutos indica que no, frente al $59 \%$ de los colegios que sí. En este caso también, teniendo en cuenta que ABIES genera un catálogo de fondos y que el $100 \%$ de los institutos y el $89 \%$ de los colegios usaban dicho programa, es probable que la persona encargada de responder el cuestionario no haya asociado ambos aspectos, de ahí el elevado porcentaje de centros que han contestado no disponer de catálogo.

18. Si la respuesta anterior es afirmativa, ¿es manual o automatizado? Opciones: Manual, Automatizado

El $75 \%$ de los institutos y el $79 \%$ de los colegios que indicaron poseer catálogos los tienen automatizados. Siguiendo el razonamiento de la pregunta 17 , si el $100 \%$ de los institutos y el $89 \%$ de los colegios usan ABIES, todos dispondrán de catálogo automatizado, por eso el $25 \%$ de los institutos y el $21 \%$ de los colegios que dicen poseerlo manual es porque, además, dispondrán de catálogo manual. 
Los catálogos que predominan en los centros educativos en general son los catálogos de autores y títulos. En este caso, en los institutos ambos catálogos son usados en el mismo porcentaje (50\% y $50 \%$ ) y en los colegios también (31\% y $31 \%$ ).

20. Para el proceso técnico del fondo (catalogación, clasificación, asignación de materias) ¿utiliza abies? Opciones: Sí, No, Ns/Nc

En el $100 \%$ de los institutos sí se utiliza ABIES para realizar el proceso técnico del fondo (ya que el $100 \%$ de los mismos está automatizado con tal programa), y en los colegios es usado por el $86 \%$ de los casos.

21. Si la respuesta anterior es negativa, ¿qué otras herramientas utiliza? Opciones: Clasificación Decimal Universal cdu, Reglas de Catalogación rc, Listas de Encabezamientos de Materia lems, Otros

Como se puede ver en la respuesta anterior, solamente el $14 \%$ de los colegios utilizan otra herramienta distinta a ABIES; de ellos, el 50 \% utiliza la CDU, el $25 \%$ las LEMS y el $25 \%$ otras herramientas ad hoc.

22. ¿Se asigna materia al material de Literatura y Ficción? Opciones: Sí, No, Ns/Nc

En muchas bibliotecas infantiles y juveniles se asigna una materia específica al material de literatura y ficción (aunque esta regla no es así para el resto de las bibliotecas). En el caso de los institutos, únicamente el $25 \%$ asignan materia al fondo de literatura y ficción, frente al $46 \%$ de los colegios de Badajoz.

23. ¿Con qué criterio se organiza el fondo de Literatura y Ficción? Opciones: cdu, Núm. de Registro, Colecciones, Otros

En muchas ocasiones, en las bibliotecas infantiles y juveniles, el fondo referente a literatura y ficción tiene una organización especial para que sea más atrayente a los niños/as. En los centros educativos de Badajoz, el $75 \%$ de los institutos utilizan la CDU para esta organización especial, y en los colegios principalmente se organizan por ciclos (38\%)

24. ¿Con qué criterio organiza el fondo de Consulta y Conocimiento? Opciones: cdu, Núm. de Registro, Colores, Símbolos icónicos, Otros

En ocasiones, en las bibliotecas infantiles y juveniles, el fondo referente a consulta y conocimiento se organiza de manera distinta al resto para que sea más fácil identificar la temática. Tanto los institutos como los colegios usan en primera opción la CDU para organizar el material de conocimiento (60 \% y 40 \%, respectivamente). Este aspecto es favorable ya que será ésta la forma de organización que los alumnos encuentren en el resto de las bibliotecas.

25. ¿Cuál es la distribución del material de la biblioteca escolar? Opciones: Estanterías abiertas, Estanterías cerradas, Almacén

Una de las principales aportaciones de la biblioteca escolar es que el alumnado pueda sentirse cómodo al buscar, consultar, preguntar, etc. Para ello, lo recomendable es que el fondo de la misma se encuentre abierto y disponible para que los usuarios puedan acceder a él libremente. La mayoría de las bibliotecas escolares en los institutos y en los colegios analizados ofrece la colección en estanterías abiertas (el 67 \% y el 76 \%, respectivamente).

D. Presencia de la biblioteca escolar en Internet

26. La biblioteca escolar, ¿tiene sitio web? Opciones: Sí, No, Ns/Nc

La actualidad se encuentra inmersa en la denominada sociedad de la información y, por tanto, los niños/ as son nativos informáticos. No conciben un mundo sin un ordenador conectado a Internet. Debido a esto es llamativo observar que el $75 \%$ de los institutos y el $45 \%$ de los colegios encuestados no posean un sitio web de su biblioteca escolar. En esta cuestión es preciso aclarar que cuando el centro indica que la biblioteca dispone de web puede ser tanto un blog de la biblioteca como un sitio web propiamente.

27. La biblioteca escolar, ¿tiene un perfil en las redes sociales (actualiza la información, novedades, etc., en ellas)? Opciones: Sí, No, Ns/Nc

Solamente tiene perfil en las redes sociales la biblioteca escolar de un instituto y de un colegio.

28. Si la respuesta anterior es afirmativa, ¿puede indicar en qué redes sociales? Opciones: Twitter, Facebook, Otros

De las dos bibliotecas que han indicado que sí tienen un perfil en las redes sociales, la del instituto se decanta por Twitter y la biblioteca del colegio por Facebook. 
29. ¿Cuál es la superficie media de la biblioteca escolar? Opción: m2

La superficie media de las bibliotecas escolares en los institutos de Badajoz es grande, siendo $120.5 \mathrm{~m}^{2}$. Esta media supera ampliamente la recomendada por el Real Decreto (R. D.) 132/2010, ${ }^{5}$ que indica un mínimo

de $75 \mathrm{~m}^{2}$ para las bibliotecas de los centros que impartan educación secundaria obligatoria o bachillerato. En el caso de los colegios encuestados, la media desciende a $43.5 \mathrm{~m}^{2}$. En esta ocasión, se acerca mucho a la superficie recomendada por el mencionado R. D. para las bibliotecas de los centros que impartan educación primaria $\left(45 \mathrm{~m}^{2}\right)$.

30. ¿Cuántas plazas (silla + mesa) tiene? Opción: Núm. de plazas

El número medio de plazas (silla + mesa) que tienen los institutos es de 47.25 puestos, lo que significa 2.55 $\mathrm{m}^{2}$ por plaza; los colegios de 23.67 puestos, lo que indica $1.84 \mathrm{~m}^{2}$ por plaza.

31. ¿Cuáles son las características físicas de la biblioteca escolar? Características: Acceso, Luz natural, Ubicación, Contaminación acústica, Mobiliario, Capacidad. Opciones: Bien, Mal, Regular, Ns/Nc

Se puede decir que los institutos y colegios encuestados se encuentran satisfechos con las características de su biblioteca escolar ya que han elegido la opción Bien como media en el 68.67 \% y 63.67 \% respectivamente.

F. Funcionamiento y gestión de la biblioteca escolar

F.1. Servicios

32. ¿De qué equipos dispone la biblioteca escolar? Opciones: PC Sobremesa, Portátiles, Fotocopiadora, Escáner, Pantallas de cine, Televisión, e-book, Otros

Los equipos que tienen mayor presencia en las bibliotecas escolares en los institutos y colegios son los ordenadores de sobremesa (37 \% y $25 \%$ respectivamente). El equipo que menos presencia tiene en los centros educativos es el e-book, siendo inexistente en los institutos y presente en un $6 \%$ de los colegios (esta presencia, aunque mínima, sorprende gratamente dada su actualidad para las bibliotecas).

33. ¿Qué uso le dan a la biblioteca escolar los alumnos? Opciones: Lectura, Préstamo, Trabajos de clase con consulta, Trabajos de clase sin consulta, Uso de ordenadores en general, Uso de ordenadores para búsqueda, Uso de ordenadores para juegos, Otros, No la usan

La lectura, el préstamo, los trabajos de clase con consulta y el uso de ordenadores en general son los más usados en los institutos aunque con un bajo porcentaje (11\%). En los colegios, la utilidad principal que hacen de la biblioteca escolar los alumnos es el préstamo y la consulta con un $15 \%$ y un $14 \%$ respectivamente. Es extraño el bajo uso que hacen de los ordenadores disponibles en la biblioteca y de las redes sociales, a pesar de encontrarse inmersos en la sociedad de la información y la tecnología. Es preocupante que en el 8 \% de los institutos y el $5 \%$ de los colegios los alumnos no usen la biblioteca.

34. ¿Qué uso le dan a la biblioteca escolar los profesores? Opciones: Lectura, Préstamo, Trabajos de clase con consulta, Trabajos de clase sin consulta, Preparación de clases, Corrección de exámenes, Uso de las tic, Consulta de bibliografía, Otros, No la usan

El uso prioritario que le da el profesorado a la biblioteca escolar es el préstamo del fondo, con un $15 \%$ en los institutos y un $14 \%$ en los colegios. En cambio, la opción que menos utilizan es la consulta de bibliografía con el $6 \%$ en los institutos y el $8 \%$ en los colegios. Es preocupante que en el $6 \%$ de los institutos y colegios el profesorado no use la biblioteca escolar.

35. ¿Qué servicios ofrece la biblioteca escolar? Opciones: Préstamo a los alumnos, Préstamo a los departamentos, Préstamo de aula, Préstamo de portátiles, Préstamo de e-book, WiFi, Actividades extraescolares, Fomento de la lectura/escritura, Fomento de las tic, Difusión de fondos, Otros, Ningún servicio

5 R. D. 132/2010, de 12 de febrero, por el que se establecen los requisitos mínimos para los centros que impartan las enseñanzas del segundo ciclo de la Educación Infantil, la Educación Primaria y la Educación Secundaria (BOE 12-3-2010). 
Los servicios más ofertados en las bibliotecas escolares de los institutos son préstamo a los alumnos (20 $\%)$, actividades extraescolares (18\%) y fomento de la lectura y escritura (15\%). En los colegios encuestados son el préstamo a los alumnos (18\%), el préstamo a las aulas (18\%) y el fomento de la lectura y escritura (16\%). Muchas de las actividades principales coinciden entre los dos tipos de centros educativos y aquellos servicios más relacionados con las tecnologías de la información y la comunicación son los menos ofertados en ambos casos (préstamo de portátiles o e-books, uso WiFi y fomento de las TIC).

\section{F.2. Aspectos económicos en la gestión}

36. ¿Existe un presupuesto específico de la biblioteca escolar? Opciones: Sí, No, Ns/Nc

Es recomendable que el centro educativo realice un presupuesto anual para la biblioteca escolar como se ve reflejado en las directrices de la IFLA/Unesco para las bibliotecas escolares (2002): " [...] El uso del presupuesto debe planearse cuidadosamente para todo el año [...]". En los institutos analizados el 50 \% sí realiza un presupuesto para la biblioteca escolar, pero el otro $50 \%$ de los encuestados no tiene ninguno. En cuanto a los colegios, el número de centros con presupuesto se eleva al 64 \%.

F.3. Gestión y tipologías del personal

37. Si la respuesta anterior es afirmativa, ¿a cuánto asciende el presupuesto anual de la biblioteca? Opción: Presupuesto anual

De los institutos y colegios que tienen un presupuesto anual para la biblioteca escolar, los institutos tienen una media de 4140,28 € y los colegios $850 €$.

38. ¿Cuál es la fecha de comienzo de la gestión de la biblioteca escolar? Opciones: <1980, 1980-1990, 1991-2000, 2001-2010, >2010, Ns/Nc

En los institutos, el mayor porcentaje de los centros comenzaron a gestionar sus bibliotecas escolares 0 antes de 1980, 0 entre 1990-2000 (25 \% en ambas opciones). En cuanto a los colegios, la mayoría de los mismos (59 \%) comienzan a gestionarla en fechas más actuales, década 2001-2010.

39. ¿Existe un responsable de la gestión de la biblioteca escolar? Opciones: Sí, No, Ns/Nc

Para que la biblioteca escolar funcione es imprescindible que alguien se encargue de gestionarla. En los institutos y colegios de Badajoz existe un responsable de su gestión en el $100 \%$ de los casos.

40. ¿Quién es el encargado de la biblioteca escolar? Opciones: Profesores de Lengua/Literatura, Otros Profesores, Bibliotecarios, Voluntarios, Monitores, Miembros de la Asociación de Madres y Padres del Centro, Otros

Antes de indicar qué figura se encarga de la biblioteca escolar en los centros encuestados, se debe recordar lo que indican las directrices de la IFLA/Unesco para las bibliotecas escolares (2002): " [...] La riqueza y la calidad de la biblioteca dependen de los recursos de personal disponibles dentro y más allá de la biblioteca escolar. Por este motivo, es de vital importancia contar con una plantilla bien formada y altamente motivada, que consista de un número suficiente de miembros según la dimensión de la escuela y sus necesidades específicas de servicio bibliotecario. La plantilla está formada por bibliotecarios titulados y bibliotecarios auxiliares. Además puede existir una plantilla de apoyo, como por ejemplo profesores, técnicos, padres y otros voluntarios. Los bibliotecarios escolares deben ser titulados y contar con una formación adicional en teoría educacional y pedagogía [...]". En el presente estudio, tanto en los institutos como en los colegios, el responsable principal de la biblioteca escolar es un profesor del centro (56 \% y $62 \%$, respectivamente), seguido en el caso de los institutos por un profesor específico en Lengua y Literatura (44\%) y en el caso de los colegios por los voluntarios (12\%), profesores de Lengua y Literatura (11\%) y personal con formación en Biblioteconomía (11\%). Es muy grave comprobar que sólo el $11 \%$ de los colegios y ninguno de los institutos tienen un responsable con formación en Biblioteconomía y Documentación.

41. Si en la respuesta anterior hay responsables Bibliotecarios, ¿cuál es su formación específica en Biblioteconomía y Documentación? Opciones: Nivel de formación

En los colegios que tienen un responsable con formación en Biblioteconomía y Documentación, uno de ellos es Licenciado y Doctorado en Documentación, otro es Licenciado en Documentación y el otro Ns/Nc.

42. ¿Cuáles son las funciones del responsable de la biblioteca escolar? Opciones: Selección y adquisición del material, Difusión de la información, Colaboración con el profesorado, Tratamiento y organización del material, Dinamización, Otros, Ninguna función 
La colaboración con el profesorado es la función más desarrollada en los institutos (25 \%), seguida muy de cerca por el tratamiento y organización del fondo de la biblioteca escolar (24\%). En los colegios, el tratamiento y organización del fondo de la biblioteca escolar es la función más desempeñada (21\%), seguida de la selección y adquisición del material (20\%).

\section{F.4. Horario de apertura}

43. ¿Tiene horario fijo de apertura? Opciones: Sí, No, Ns/Nc

Es un dato muy esperanzador que el $100 \%$ de los institutos y el $91 \%$ de los colegios tengan una biblioteca escolar con un horario fijo de apertura.

44. ¿Cuántas horas semanales de apertura tiene? Opciones: <10 horas, 10-20 horas, 21-30 horas, 31-40 horas, $>40$ horas

De todos aquellos centros educativos que tienen un horario de apertura fijo, en el caso de los institutos el 63 $\%$ abren de 10-20 horas semanales; en los colegios la mayoría se centra en dos franjas horarias: un $41 \%$ abre menos de10 horas semanales y otro $41 \%$ abre entre $21-30$ horas a la semana.

Una vez analizada la situación global de las bibliotecas escolares de la ciudad de Badajoz, se elabora un ranking que permite conocer la situación particular de cada biblioteca. Para ello se matizan y depuran las 44 cuestiones iniciales atendiendo a determinados criterios, luego de lo cual se reducen a 32 (Tabla V). Se anota la presencia (1) o ausencia (0) de cada cuestión en el modelo relleno. Con el fin de no premiar/perjudicar doblemente a los centros con presencia/ausencia de cada cuestión, aquéllas que derivan o puntúan en otras no se tienen en cuenta para el ranking, por ello no aparecen en la tabla.

Tabla V. Plantilla para establecer el ranking de las bibliotecas escolares según su situación actual.

\begin{tabular}{|l|l|l|}
\hline Núm. & \multicolumn{1}{|c|}{ Cuestión } & \multicolumn{1}{c|}{ Criterio } \\
\hline 1 & El centro tiene biblioteca central o central+aula & IFLA/Unesco (2002) recomienda centralizada \\
\hline 3 & La biblioteca sirve a los alumnos & Indispensable \\
\hline 4 & Existe un plan de trabajo anual & Indispensable \\
\hline 5 & La biblioteca tiene relación con la biblioteca pública & Indispensable \\
\hline 6 & La biblioteca tiene relación con el cPR & Indispensable \\
\hline 7 & $\begin{array}{l}\text { El contenido de la biblioteca tiene material de } \\
\text { consulta y ficción }\end{array}$ & IFLA/Unesco (2002): ambos indispensable \\
\hline 8 & $\begin{array}{l}\text { Núm. de volúmenes en la franja 1000-3000 0 } \\
\text { superior }\end{array}$ & IFLA/Unesco (2002): mínimo 2500 \\
\hline 9 & La biblioteca realiza revisión anual del material & Indispensable \\
\hline 12 & Núm. de fondos de ingreso anual superior a 300 & IFLA/Unesco (2002): mínimo 300 \\
\hline 13 & Los fondos están automatizados & Indispensable \\
\hline 15 & La biblioteca tiene libro de registro de fondos & Indispensable \\
\hline 17 & La biblioteca dispone de catálogos & Indispensable \\
\hline 20 & $\begin{array}{l}\text { La biblioteca usa ABIES para el proceso técnico del } \\
\text { material }\end{array}$ & Indispensable \\
\hline
\end{tabular}




\begin{tabular}{|c|c|c|}
\hline 22 & $\begin{array}{l}\text { La biblioteca asigna materia al fondo de literatura y } \\
\text { ficción }\end{array}$ & Indispensable \\
\hline 23 & $\begin{array}{l}\text { El fondo de literatura y ficción no se organiza por } \\
\text { núm. de registro }\end{array}$ & Indispensable \\
\hline 24 & $\begin{array}{l}\text { El fondo de consulta/conocimiento se organiza por } \\
\text { CDU }\end{array}$ & Indispensable \\
\hline 25 & El material se distribuye en estanterías abiertas & Indispensable \\
\hline 26 & La biblioteca dispone de página web & Indispensable \\
\hline 27 & La biblioteca tiene un perfil en las redes sociales & Indispensable \\
\hline 29 & La superficie de la biblioteca es superior a $45 \mathrm{~m}^{2}$ & R. D. $132 / 2010{ }^{6}$ mínimo $45 \mathrm{~m}^{2}$ \\
\hline 30 & La biblioteca conoce el número de plazas que tiene & Indispensable \\
\hline 31 & $\begin{array}{l}\text { Las características físicas de la biblioteca escolar } \\
\text { son buenas }\end{array}$ & Indispensable \\
\hline 32 & $\begin{array}{l}\text { El equipo informático fundamental de la biblioteca es } \\
\text { el PC de sobremesa }\end{array}$ & Indispensable \\
\hline 33 & $\begin{array}{l}\text { Los alumnos usan algún tipo de servicio ofrecido por } \\
\text { la biblioteca }\end{array}$ & Indispensable \\
\hline 34 & $\begin{array}{l}\text { Los profesores usan algún tipo de servicio ofrecido } \\
\text { por la biblioteca }\end{array}$ & Indispensable \\
\hline 35 & $\begin{array}{l}\text { La biblioteca ofrece servicio de préstamos y/0 } \\
\text { consulta (lectura y escritura) }\end{array}$ & Indispensable \\
\hline 36 & $\begin{array}{l}\text { Existe un presupuesto específico destinado a la } \\
\text { biblioteca }\end{array}$ & Indispensable \\
\hline 38 & La biblioteca se empezó a gestionar antes de 2010 & LOE 2/2006: ${ }^{7}$ respalda las BE \\
\hline 39 & Existe un responsable de la gestión de la biblioteca & Indispensable \\
\hline 40 & $\begin{array}{l}\text { El responsable es un bibliotecario (formación en } \\
\text { Biblioteconomía y Documentación) }\end{array}$ & Puntúa, dada su importancia \\
\hline 42 & $\begin{array}{l}\text { Función básica del responsable: tratamiento de la } \\
\text { información y organización de la biblioteca }\end{array}$ & Indispensable \\
\hline 43 & La biblioteca tiene horario fijo de apertura & Indispensable \\
\hline
\end{tabular}

En la Gráfica 1 se observa el ranking de las bibliotecas escolares según su situación actual. De los 32 puntos que las bibliotecas podían obtener en las 32 cuestiones analizadas, la media en los institutos fue de 21.62 y en los colegios de 22.05 .

Como se observa en la distribución, en la parte más elevada se encuentran el CEIP Arias Montano con 30 puntos y en segundo lugar, con 27 puntos, el IES Bárbara de Braganza y los CEIP Manuel Pacheco, Luis de Morales y N. Sra. de Fátima. En la parte final del ranking se encuentra en último lugar

6 R. D. 132/2010, de 12 de febrero, por el que se establecen los requisitos mínimos para los centros que impartan las enseñanzas del segundo ciclo de la Educación Infantil, la Educación Primaria y la Educación Secundaria (BOE 12-3-2010)

7 LOE Ley Orgánica 2/2006, de 3 de mayo, de Educación (BOE 4/5/2006). 
la biblioteca escolar del CEIP Santa Marina con 14 puntos, seguida por la biblioteca del colegio Jesús Obrero con 16 puntos.

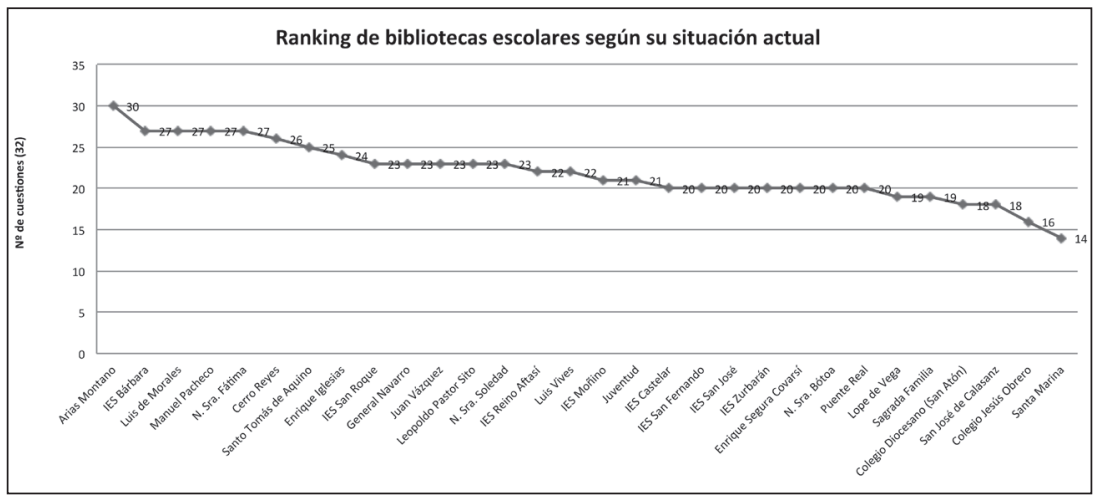

Gráfica 1. Ranking de las bibliotecas de los institutos y los colegios de la ciudad de Badajoz según su situación actual (2012).

\section{Evaluación de los sitios web de las bibliotecas escolares}

El análisis de los sitios web de las bibliotecas escolares de los centros educativos se realizó utilizando la plantilla diseñada en Metodología y anotando el grado de cumplimento de cada característica en cada sitio web, tal y como se ha comentado en el párrafo correspondiente. De las 30 bibliotecas escolares que colaboraron en este estudio, únicamente 12 poseen sitio web (9 CEIP, 1 colegio privado/concertado y 2 IES). En algunos casos, se ha tomado como referencia para analizar el sitio web de las bibliotecas escolares los blogs de las mismas, ya que el propio centro educativo así lo ha indicado al hacer mención a un sitio web de la biblioteca.

El estudio comprueba que el cumplimiento de las características generales en las webs de las bibliotecas analizadas es mucho mayor que el de sus características específicas (con una media respectiva de 9.55 frente a 5.15 sobre 12) puesto que entre las características más utilizadas se encuentran el Uso de una adecuada gramática y ortografía, Fácil navegación o No sobrecarga informativa. Por el contrario, entre las menos utilizadas se hallan el uso de una Web multilingüe, Interacción con el alumnado o Apoyo en línea.

La Gráfica 2 muestra el ranking de los sitios web que tienen las bibliotecas escolares de los centros educativos atendiendo a las 30 características que incluyen (10 generales +20 específicas). De los 30 puntos que las webs de las bibliotecas podían obtener en las características analizadas, la media general en institutos y colegios fue de 16.54. Si se analiza la gráfica se observa que en 
la parte más elevada de la distribución, que tiene las máximas puntuaciones, se encuentran las bibliotecas escolares de los CEIP Arias Montano (22 puntos) y Luis Vives (21.5 puntos) y el IES Bárbara de Braganza (21 puntos). Con respecto a las bibliotecas escolares situadas en la parte más baja de la distribución y que obtienen las menores puntuaciones, se encuentran los CEIP Nuestra Sra. de Fátima (9 puntos) y Nuestra Sra. de la Soledad (11.5 puntos) y el IES San Roque (12 puntos).

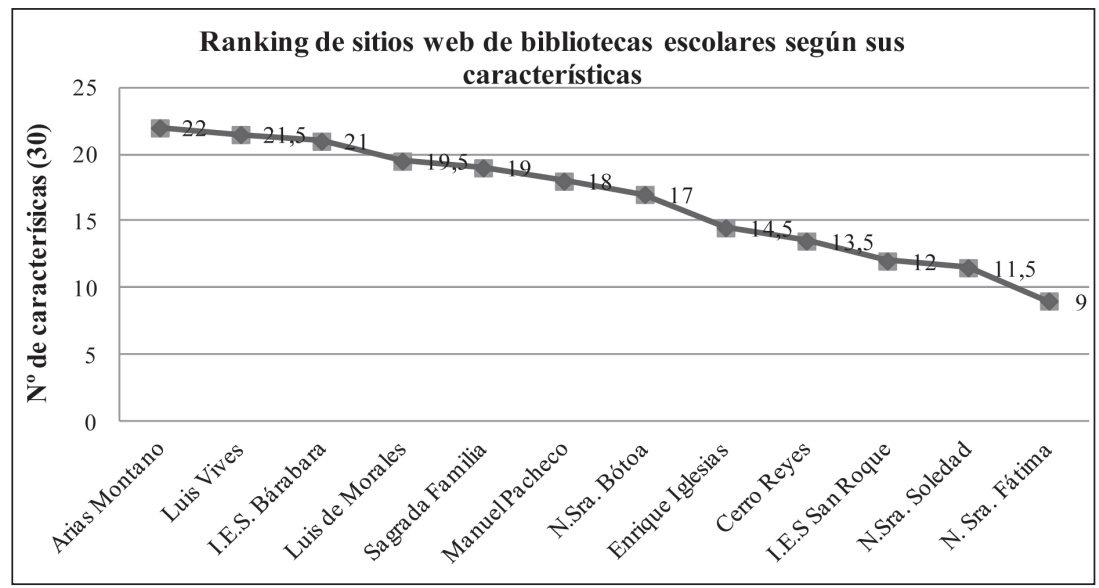

Gráfica 2. Ranking de los sitios web de las bibliotecas de los institutos y colegios de la ciudad de Badajoz, según sus características (2012).

Finalmente, se calculó la correlación Pearson entre los rankings de las bibliotecas escolares según la puntuación obtenida en la situación actual de éstas y su evaluación web. Evidentemente sólo se ha comprobado la relación en el caso de las 12 bibliotecas escolares representadas en la web, las que, por consiguiente, han participado en ambos rankings. La correlación Pearson hallada entre ambas variables es muy baja $(\mathrm{r}=0.1)$.

\section{Conclusiones}

Se ha diseñado un modelo exhaustivo de indicadores de evaluación para comprobar la situación de las bibliotecas escolares con un total de 44 cuestiones, y un modelo para evaluar los sitios web de las mismas con 30 características (10 generales y 20 específicas). Al aplicarse dichos modelos en las bibliotecas de los centros escolares de la ciudad de Badajoz (tasa de participación del $61.22 \%$ ), de sus resultados se obtuvieron las conclusiones que se presentan a continuación. 


\section{Situación actual}

En general, la biblioteca escolar tiene un papel destacado en el centro educativo, pero aún así su potencial no está lo suficientemente explotado. La puntuación media de las bibliotecas con respecto a su situación actual roza lo notable, tanto en los institutos (21.62 puntos: $67.6 \%$ ) como en los colegios (22.05 puntos: $69 \%$ ).

Los aspectos favorables de la situación actual de las bibliotecas son los siguientes:

- Se ofrecen numerosos servicios, tanto al alumnado como al profesorado, e incluso a otros colectivos (ex-alumnos, PAS, etc.). Hacen hincapié en el préstamo de material, realizan actividades extraescolares y fomentan la lectura y escritura.

- Llevan a cabo un plan de trabajo anual y tienen destinado un presupuesto específico, por lo que se pueden planificar con antelación gastos al planificar las actividades.

- Tienen un amplio fondo documental que se revisa anualmente, lo que permite un sólido control del mismo. Utilizan el programa ABIES, que facilita la recopilación y control del material.

- Permiten que el fondo sea consultado libremente por todos los usuarios, y aunque sigue existiendo un gran porcentaje de bibliotecas que tienen su acceso controlado, este hecho va descendiendo.

En cuanto a los aspectos desfavorables, tenemos que:

- En la mayoría de los casos el encargado de la biblioteca es un profesor. Es muy necesaria la figura de un bibliotecario con formación en Biblioteconomía y Documentación con dedicación completa, ya que unas horas a la semana no son suficientes para que las necesidades de la biblioteca escolar sean atendidas.

- Sería muy favorable un mayor acercamiento entre las bibliotecas escolares y públicas, ya que sería muy benéfico para el alumnado y constituye un aspecto muy poco potenciado actualmente.

- Las herramientas más usadas por los jóvenes son las nuevas tecnologías de la información y la comunicación, y en este sector la biblioteca escolar no aprovecha todo el potencial, pues aunque una de las maneras más fáciles de acercarse al alumnado es a través de Internet la mayoría de los centros educativos no tienen página web de la biblioteca, ni un perfil en las redes sociales. Si potenciaran estas herramientas 
la biblioteca sería más atrayente y existiría una implicación mayor por parte de los usuarios.

La biblioteca con la puntuación más elevada en cuanto su estado actual ha sido la del CEIP Arias Montano y la más desfavorable corresponde al CEIP Santa Marina.

\section{Sitios web}

La puntuación media obtenida por las webs de las bibliotecas escolares atendiendo a las características que cumplen apenas supera el aprobado (16.54 puntos: $55.14 \%)$.

El cumplimiento de las características generales en las webs de las bibliotecas analizadas es mucho mayor que el de sus características específicas, lo que incita a seguir trabajando en el diseño de modelos de evaluación específicos para webs de bibliotecas escolares y a transmitir los resultados de las investigaciones a los responsables de los centros escolares para que tomen medidas al respecto.

La tendencia general observada es que las características específicas acerca del fomento de la lectura son las que más peso tienen en los sitios web analizados. Esto significa que la biblioteca escolar se ha esforzado por ser un punto de referencia de lectura para el alumnado, aspecto que se ve reflejado en sus propias recomendaciones de lectura para determinadas franjas de edad, o con enlaces a blogs y sitios web sobre cuentos, novelas, etcétera.

El contenido que ofrecen los sitios web de las bibliotecas escolares es fácil de leer ya que intentan no sobrecargarlo con aportaciones muy amplias; sin embargo, se ha observado una falta de contenidos en otros idiomas, lo que facilitaría la consulta para los alumnos extranjeros.

Se ha comprobado una carencia, tanto en las actividades para el autoaprendizaje de los niños como en el fomento del uso de las nuevas tecnologías. Estos vacíos repercuten directamente en la interacción del alumnado con el sitio web de la biblioteca escolar, que básicamente es inexistente. Esto puede ser debido a que hay una gran ausencia de apoyo en línea por parte de los administradores del sitio web, lo que dificulta dicha interacción.

La web bibliotecaria con mayor puntuación es la del CEIP Arias Montano y la que tiene la menor es la del CEIP Nuestra Sra. de Fátima.

\section{Conclusión final}

Finalmente, se ha comprobado que la correlación entre las bibliotecas escolares atendiendo a su situación actual y al estado de sus páginas web es muy 
baja $(\mathrm{r}=0.1)$, por lo que no se puede corroborar la hipótesis de partida y considerar que las bibliotecas escolares que mejor funcionan actualmente en la ciudad de Badajoz son también las que mejores webs poseen (a pesar de que el CEIP Arias Montano sí obtiene las máximas puntuaciones en ambos rankings.

\section{Bibliografía}

Alonso, J. (2007-2008), "Comunicar en el Web: Propuesta de Criterios para Analizar Sitios en Internet", en Teknokultura: Revista On-line, 7:1-14, disponible en: http://teknokultura.uprrp.edu/pdf /alonso.pdf (Fecha de consulta: 01/10/2012).

ALA (American Library Association), Presidential Committee on Information Literacy (1989), Final Report, Chicago: American Library Association, disponible en: http://www.ala.org/acrl/publications/ whitepapers/presidential (Fecha de consulta: 12/10/2012).

Chao, H. (2002), "Assessing the quality of academic libraries on the Web: the development and testing of criteria", en Library \& Information Science Research, 24:169-194.

Clyde, L. A. (2004), "School library Web sites: 1996-2002", en The Electronic Library, 22(2):158-167.

Codina, L. (2000), "Evaluación de recursos digitales en línea: conceptos, indicadores y métodos", en Revista Española de Documentación Científica, 23(1):9-44.

Crespo, S. (2007), "Archivos Históricos Provinciales en la red: análisis y evaluación”, en Boletín de la ANABAD, 57(1):497-512.

Cruz Solís, Antonio Miguel de la (2008), Las bibliotecas escolares en Extremadura: antecedentes, análisis de la situación actual, necesidades e instrumentos para su implantación en el sistema educativo de la Comunidad, tesis doctoral, Universidad de Extremadura, España.

Díaz Sanchez, E.; Martín-Consuegra Navarro, D. y Esteban Talaya, A. (2008), "Evaluación de la eficacia de las páginas web", en Emilio José de Castro Silva y Francisco José Díaz de Castro (coords.), Universidad, Sociedad y Mercados Globales, disponible en: http:// dialnet.unirioja.es/servlet/articulo? codigo $=2751745$ (Fecha de consulta: 05/11/2012).

Faba-Pérez, C. (2000), "Las bibliotecas escolares y Extremadura: un estudio comparativo nacional e internacional", en Boletín de la ANABAD, 50(2):119-133.

Faba-Pérez, C.; Guerrero-Bote, V. y Moya-Anegón, F. (2004), Fundamentos y técnicas cibermétricas, Mérida: Junta de Extremadura.

González, M. P.; Lorés, J. y Pascual, A. (2001), Evaluación heurística, Universidad de Lleida, disponible en: http://www.aipo.es/libro/ pdf/15-evaluacion-heuristica.pdf (Fecha de consulta: 01/12/2012). 
González-Lucio, J. A.; Faba-Pérez, C.; Moya-Anegón, F. y Moscoso-Castro, P. (2009), "Evolution of the formal quality indicators of the Web spaces of University Libraries in Spain", en Cybermetrics: International Journal of Scientometrics, Informetrics and Bibliometrics, 13(1):1-11.

Hassan Montero, Y. y Martín Fernández, F. J. (2003), "Guía de evaluación heurística de sitios Web”, en No sólo usabilidad, 2:1-7, disponible en: http://nosolousabilidad.com/articulos/heuristica.htm (Fecha de consulta: 12/10/2012).

IFLA (International Federation of Library Associations and Institutions) (2002), The IFLA/Unesco School Library Guidelines, disponible en: http://archive.ifla.org/VII/s11/pubs/sguide02-s.pdf (Fecha de consulta: 20/09/2012).

Jiménez Fernández, C. (2012), "Aspectos informativos básicos en la web de la biblioteca escolar", en Revista Didáctica, Innovación y Multimedia, 24:1-10, disponible en: http://ddd.uab.cat/pub/dim/ dim_a2012m12n24/dim_a2012m12n24a4.pdf (Fecha de consulta: $2 / 01 / 2013)$.

Jiménez Piano, M. (2001), “Evaluación de sedes Web”, en Revista Española de Documentación Científica, 24(4):405-431.

Junta de Extremadura, Dirección General de Política Educativa (2006) (ed.), "Análisis de la situación actual de las bibliotecas escolares extremeñas de los centros públicos”, en Pinakes, 1:17-18.

Kim, H. y Lee, H. (2007), "Digital-age trends and perspectives in Korean university archives", en The Electronic Library, 27(3):426-440.

Large, J. A. y Beheshti, J. (2005), "Interface Design, Web Portals, and Children”, en Library Trends, 54(2):318-342.

Las bibliotecas escolares en España: análisis de resultados del estudio sobre su situación (1997), Madrid: ANABAD, FESABID y Ministerio de Cultura.

Marchesi, A. y Miret, I. (2005) (dir.), Las Bibliotecas escolares en España: análisis y Recomendaciones, Salamanca: FGSR.

Marquès Graells, P. (1999), Los espacios web multimedia: tipología, funciones, criterios de calidad, disponible en: http://peremarques. pangea.org/tipoweb.htm (Última revisión: 03/08/10. Fecha de consulta: 10/11/2012).

- (2001), Los portales educativos: ficha para su catalogación y evaluación, disponible en: http://peremarques.pangea.org/evaport2. htm (Última revisión 28/08/04. Fecha de consulta: 12/11/2012).

Más Bleda, A. y Chaín Navarro, C. (2009), "Los usuarios y las webs de los archivos históricos nacionales: el caso del Arquivo Nacional da Torre do Tombo (Portugal)", en Investigación Bibliotecológica: archivonomía, bibliotecología e información, 23 (47):189-212.

Ministerio de Educación, Comisión Técnica de Bibliotecas Escolares (2011), Marco de referencia para las bibliotecas escolares, Madrid: Ministerio de Educación, Subdirección General de Información y Publicaciones. 
Pinto, M.; Alonso Berrocal, J. L.; Cordón García, J. A.; Fernández Marcial, V.; García Figuerola, C.; García Marco, J.; Gómez Camarero, C. y Zazo Rodríguez, A. F. (2005), "Quality assessment of Spanish universities' web sites focused on the European Research Area", en Scientometrics, 65 (1):67-93.

Pomet Correa, Alfonso (2006), "Panorama de las bibliotecas escolares en Extremadura: Educación Secundaria", en Boletín del Observatorio del libro y la Lectura de Extremadura, 6:1-4.

Roba Stuart, O. (2003), "Archivos de datos en línea para ciencias sociales”, en El Profesional de la Información, 12 (5):400-410.

Rodríguez Palchevich, D. R. (2010), Blogs de bibliotecas escolares argentinas, tesina de grado, Universidad Nacional de Mar del Plata, Argentina, disponible en: http://eprints.rclis.org/15135/1/TesinaDiana-versionfinal.pdf (Fecha de consulta: 26/11/2012).

Sanz-Caballero, I. y Faba-Pérez, C. (2012), "Diseño de un modelo basado en criterios e indicadores de características para la evaluación de los sitios web de archivos", en Revista General de Información y Documentación, 22:307-331.

Tejero Aparicio, A. (2006), "Panorama de las bibliotecas escolares en Extremadura: Educación Infantil y Primaria”, en Boletín del Observatorio del libro y la Lectura de Extremadura, 5:1-4.

Zhang, P. y Dran, G. M. von (2000), "Satisfiers and dissatisfiers: a two factor model for website design and evaluation", en Journal of the American Society for Information Science, 51(14):1253-1268. 